\title{
SISTEM ANTRIAN LOKET, KIOSK DAN ANDROID TERINTEGRASI SIMRS RSUD PATUT PATUH PATJU GERUNG
}

\author{
Wahyu Ramadhan \\ Universitas Bumi Gora \\ wahyurama24@gmail.com
}

\begin{abstract}
Abstrak - Lombok barat adalah salah satu kabupaten di Nusa Tenggara Barat yang bergerak dinamis dan terus maju, dengan banyak potensi yang perlu kita kembangkan untuk membangun wilayah Kabupaten Lombok Barat menjadi sebuah Kabupaten yang mampu bersaing dengan Kabupaten-Kabupaten lain di Indonesia. Layanan kesehatan seperti Rumah Patut Patuh Patju pun harus bersiap diri. Saat ini pasien yang telah merasakan penyakit, harus dipersulit dengan sistem pendaftaran pasien yang konvensional. Pasien adalah seseorang yang menerima pelayanan medik dari Rumah Sakit atau dokter, karena menderita suatu penyakit. Biasanya seorang pasien mempunyai tingkat kesabaran yang rendah. Untuk itu perlu ada terobosan dari rumah sakit atau pelayanan medik yang dapat memberikan kenyaman pasien dalam berobat. Dengan memiliki Sistem Pendaftaran Antrian Pasien Online pada suatu rumah sakit atau layanan medik, dalam pelayanan pada pasien akan teratur, sehingga menimbulkan kenyaman pada pasien. Karena fitur dari Sistem Pendaftaran Antrian Pasien Online memudahkan pasien untuk mengetahui nomor antrian yang diperoleh dan secara realtime mengetahui nmor antrian yang sedang berjalan berdasarkan klinik yang dituju. Sehingga memberikan kesempatan pada Pasien untuk me-manajemen waktunya.
\end{abstract}

Kata Kunci: web, android, mesin antrian, python, SIMRS.

\section{LATAR BELAKANG}

Lombok barat adalah salah satu kabupaten di Nusa Tenggara Barat yang bergerak dinamis dan terus maju, dengan banyak potensi yang perlu kita kembangkan untuk membangun wilayah Kabupaten Lombok Barat menjadi sebuah Kabupaten yang mampu bersaing dengan Kabupaten-Kabupaten lain di Indonesia. Sehingga peningkatan jumlah penduduk dan pariwisata tidak dapat dihindari, untuk itu fasilitas pelayanan publik khususnya dibidang kesehatan mutlak dibutuhkan. Untuk pelayanan kesehatan secara praktis dan optimal, dibutuhkan pemanfaatkan teknologi sebagai pendukung layanan.

Survei yang dilakukan oleh Asosiasi Penyelenggara Jaringan Internet Indonesia (APJII) mengungkap bahwa lebih dari setengah penduduk Indonesia kini telah terhubung ke internet. Survei yang dilakukan sepanjang 2018 itu menemukan bahwa 171,17 juta orang Indonesia telah terhubung ke internet. Adapun total penduduk Indonesia sendiri sebanyak 264,14 juta orang. Jumlah penduduk Indonesia yang mencapai 264 juta jiwa adalah pasar yang besar. Pengguna smartphone Indonesia juga bertumbuh dengan pesat. Lembaga riset digital marketing Emarketer memperkirakan pada 2018 jumlah pengguna aktif smartphone di Indonesia lebih dari 100 juta orang. Dengan jumlah sebesar itu, Indonesia akan menjadi negara dengan pengguna aktif smartphone terbesar keempat di dunia setelah Cina, India, dan Amerika.[1]

Seiring dengan perkembangan tersebut, RSUD Patut Patuh Patju (TRIPAT) Kab. Lombok Barat sebagai salah satu fasilitas pelayanan publik di Kab. Lombok Barat berbenah khususnya dibidang teknologi. Karena dengan teknologi pelayanan Rumah sakit dapat dinikmati dari manapun dan kapanpun. Meningkatnya kemajuan teknologi dan pembangunan diharapkan mampu meningkatkan kualitas kesehatan penduduk secara signifikan dan mampu menurunkan angka kematian. Upaya kesehatan yang semula di titik beratkan pada upaya penyembuhan penyakit, secara berangsur-angsur berkembang kearah keterpaduan upaya kesehatan yang menyeluruh. Kebutuhan untuk memperoleh informasi yang cepat, akurat, dan

Sistem Antrian Loket, KIOSK dan Android Terintegrasi SIMRS RSUD Patut Patuh Patju Gerung 
tepat waktu merupakan hal yang tidak dapat dihindari, sehingga Pengembangan Digital Government Service (DGS) di lingkup pemerintahan saat ini merupakan salah satu tuntutan yang harus dipenuhi dalam rangka menciptakan pelayanan kepada publik yang cepat, transparan, akuntabel dan tepat waktu. Untuk itu pemerintah harus mampu memenuhi standar pelayanan dan tuntutan masyarakat yang berbeda namun berkaitan erat.

Layanan kesehatan seperti Rumah Patut Patuh Patju pun harus bersiap diri. Saat ini pasien yang telah merasakan penyakit, harus dipersulit dengan sistem pendaftaran pasien yang konvensional. Pasien adalah seseorang yang menerima pelayanan medik dari Rumah Sakit atau dokter, karena menderita suatu penyakit. Biasanya seorang pasien mempunyai tingkat kesabaran yang rendah. Untuk itu perlu ada terobosan dari rumah sakit atau pelayanan medik yang dapat memberikan kenyaman pasien dalam berobat. Dengan memiliki Sistem Pendaftaran Antrian Pasien Online pada suatu rumah sakit atau layanan medik, dalam pelayanan pada pasien akan teratur, sehingga menimbulkan kenyaman pada pasien. Karena fitur dari Sistem Pendaftaran Antrian Pasien Online memudahkan pasien untuk mengetahui nomor antrian yang diperoleh dan secara realtime mengetahui nmor antrian yang sedang berjalan berdasarkan klinik yang dituju. Sehingga memberikan kesempatan pada Pasien untuk me-manajemen waktunya.

Di pihak RSUD PATUT PATUH PATJU akan mendapatkan keuntungan yang begitu besar, selain dapat dipermudah dalam proses antrian, sebagai rumah sakit yang akan memperoleh perhatian dari masyarakat tentunya. Karena kemudahan yang berbasis teknologi sehingga begitu dekat dengan masyarakat atau pasien khususnya. Sistem ini juga dapat membuat roda pengelolaan rumah sakit berputar dengan efisien, cepat dan akurat. Kebutuhan akan penyimpanan data pasien yang sangat besar dan terjamin serta kemudahan pengaksesan dan pengelolaan data.

Untuk itu Sistem Pendaftaran antrian Pasien Online yang support dengan Android di RSUD PATUT PATUH PATJU mutlak dibutuhkan. Sistem ini memudahkan pasien dalam mendaftarkan diri ke layanan atau klinik yang tersedia, dari mana dan kapan saja. Dan memudahkan pula petugas rumah sakit dalam persiapan pelayanan dan menciptakan kenyamanan bagi para pasien.

\section{LANDASAN TEORI}

\section{A. Internet}

Perkembangan teknologi sekarang ini telah melahirkan sumber daya informasi yang tidak dibatasi oleh ruang dan waktu. Sumber daya informasi tersebut adalah internet. Internet dapat memberikan informasi yang kita butuhkan. Penemuan internet telah menjadikan solusi dimana individu-individu maupun organisasi yang ada dapat berkomunikasi dengan mudah. Namun ada sisi buruk internet sendiri yang merupakan sarana atau media global untuk segala segala apa yang ada di dunia ini baik dalam bentuk kejahatan maupun kebaikan. Di samping itu tentunya pornografi yang semakin menjamur dan sulit dibendung telah memasuki media internet. Internet adalah metode yang menghubungkan berbagai komputer ke dalam satu jaringan komputer global, melalui protokol yang disebut TCP/IP (Transmission Control Protocol/Internet Protocol). Protokol adalah suatu petunjuk yang menggunakan pekerjaan yang akan user lakukan dengan internet, apakah akan mengakses website, melakukan transfer file mengirim e-mail dan sebagainya. Protokol dapat dibayangkan seperti suatu bahasa yang digunakan untuk berkomunikasi berbagai jenis komputer maupun sistem operasi yang terhubung di internet[4].

\section{B. Python}

Python merupakan bahasa pemrograman yang berorientasi objek dinamis yang dapat digunakan untuk bermacam-macam pengembangan perangkat lunak seperti yang dapat kita lihat pada sumber, Python menyediakan dukungan yang kuat untuk integrasi dengan bahasa pemrograman lain dan alat-alat bantunya. Python hadir dengan pustaka-pustaka standar yang dapat diperluas serta dapat dipelajari hanya dalam beberapa hari. Python meningkatkan kualitas pengembangan karena kode sumber yang mereka tulis dapat terus dipelihara.

Python dapat berjalan dibanyak platform/sistem operasi seperti Windows, Linux/Unix, Mac OS X,

Sistem Antrian Loket, KIOSK dan Android Terintegrasi SIMRS RSUD Patut Patuh Patju Gerung 
OS/2, Amiga, Palm Handhelds dan telepon genggam Nokia. saat ini Python juga telah di porting kedalam mesin virtual Java dan .NET Python didistribusikan dibawah lisensi OpenSource yang disetujui OSI (OpenSource Initiatives), sehingga Python bebas digunakan, gratis digunakan, bahkan untuk produk-produk komersil. Yayasan Perangkat Lunak Python - Python Software Foundation (PSF) memegang dan melindungi hak atas kekayaan intelektual dibawah Python, tertuang dalam konferensi PyCon, serta mendanai proyek-proyek pada komunitas Python.[3]

\section{MySQL}

MySQL adalah salah satu aplikasi RDBMS (Relational Database Management System). Aplikasi yang digunakan untuk menyimpan data walaupun dapat digunakan file teks sebagai media penyimpanan data, namun aplikasi database ini memiliki beberapa kelebihan. Akses data yang lebih cepat adalah salah satunya. MySQL sudah dikembangkan sejak akhir tahun 70-an dan baru tahun 1996 tersedia untuk publik. MySQL merupakan salah satu aplikasi Open Source. Seperti database server lainnya, MySQL dapat digunakan oleh multi user. Setiap user memiliki account yang dapat dipakai untuk mengakses MySQL server. MySQL menggunakan bahasa standar database, yaitu SQL (Structured Query Language). Python sangat mendukung database ini. Semua fungsi untuk akses ke MySQL sudah terintegrasi ke dalam engine Python dan Object Relational Mappers (ORMs) sebagai library yang memudahkan dalam membangun sistem karena library tersebut meng-otomatisasi kode berhubungan antar tabel database.

\section{Website}

Perkembangan Teknologi Informasi (TI) berkembang sangat pesat. Pesatnya perkembangan TI menjadikan teknologi internet sebagai alat komunikasi utama yang sangat diminati oleh masyarakat. Dengan adanya teknologi internet akan mempermudah dan mempercepat pencarian informasi, salah satu sumber informasi yang dapat dijadikan rujukan adalah website (William, \& Sri, 2015).

Website adalah kumpulan dari halamanhalaman situs, yang terangkum dalam sebuah domain atau subdomain, yang tempatnya berada di dalam World Wide Web ( WWW ) di dalam internet (Josi, 2016), website juga dapat diartikan sebagai sebuah halaman yang berisi data, baik data text, gambar, suara dan lainya yang dapat diakses secara online. ada banyak model pengembangan sistem yang bisa dimanfaatkan untuk membangun website salah satunya model Prototyping.

Informasi khususnya pada bidang website yang saat ini menjadi media informasi yang menawarkan berbagai kemudahan dalam menyajikan informasi. Kecepatan dan kenyamanan merupakan nilai positif adanya internet (Sudarto, 2018).

Menurut Tim EMS (2014:1) website adalah apa yang anda lihat via browser, sedangkan yang disebut web sebenarnya adalah sebuah aplikasi web, karena melakukan action tertentu dan membantu anda melakukan kegiatan tertentu.

E. Kotlin

Kotlin merupakan bahasa

Pemrograman modern yang bersifat staticallytyped yang dapat di jalankan di atas platform Java Virtual Machine (JVM). Kotlin juga dapat di kompilasi (compile) ke dalam bentuk JavaScript. JetBrains selain Kotlin ini yang juga mengembangkan salah satu tools pemrograman (IDE) yang saat ini di adopsi oleh google untuk di gunakan sebagai tools pengembangan aplikasi di Android (Android Studio).[2]

\section{ANALISA DAN PERANCANGAN SISTEM}

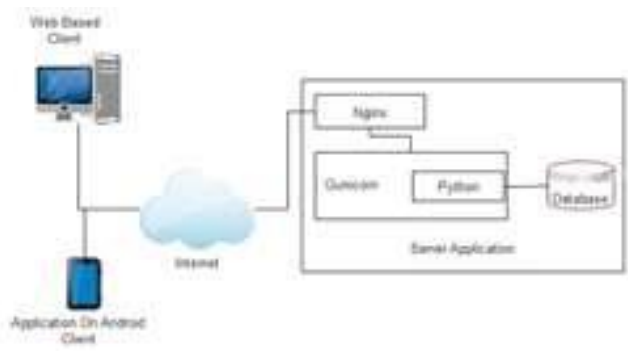

Gambar 1. Skema Rancangan Sistem

Gambar 1. Merupakan rancangan system yang akan mengintegrasikan user android dengan sistem antrian dan system informasi manajemen rumah sakit (SIMRS) ngan menggunakan webserver NGINX dibantu gunicorn untuk memberikan optimalisasi kerja webserver yang mendukung python untuk core sistemnya. 


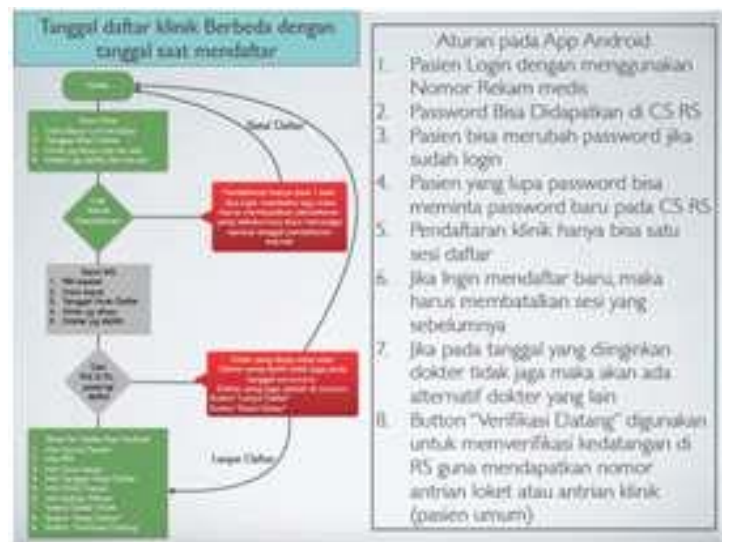

Gambar 2. Alur daftar klinik berbeda tanggal dengan saat mendaftar.

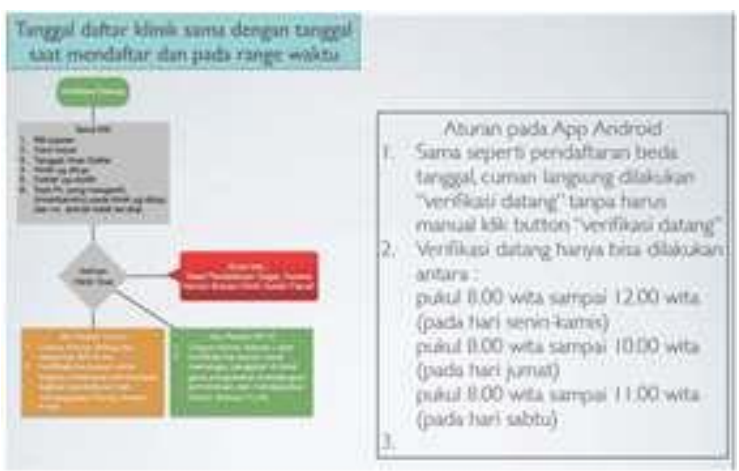

Gambar 3. Alur daftar klinik sama tanggal dengan saat mendaftar

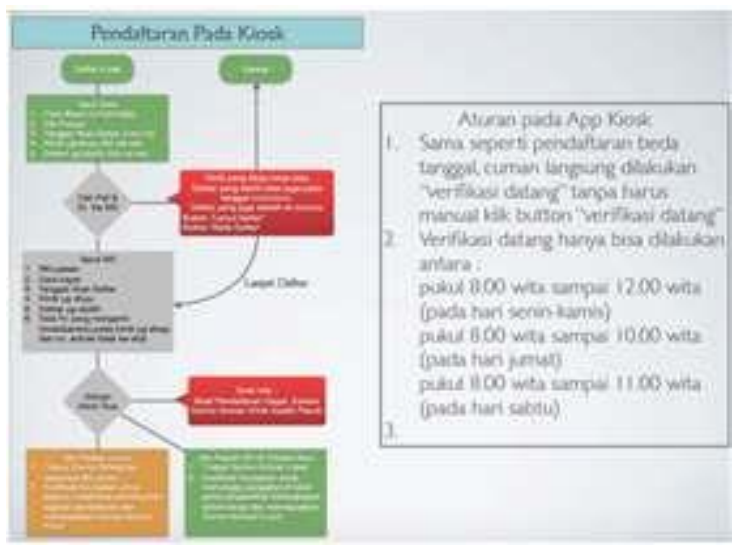

Gambar 4 Alur Proses sistem antrian loket berbasis KIOSK

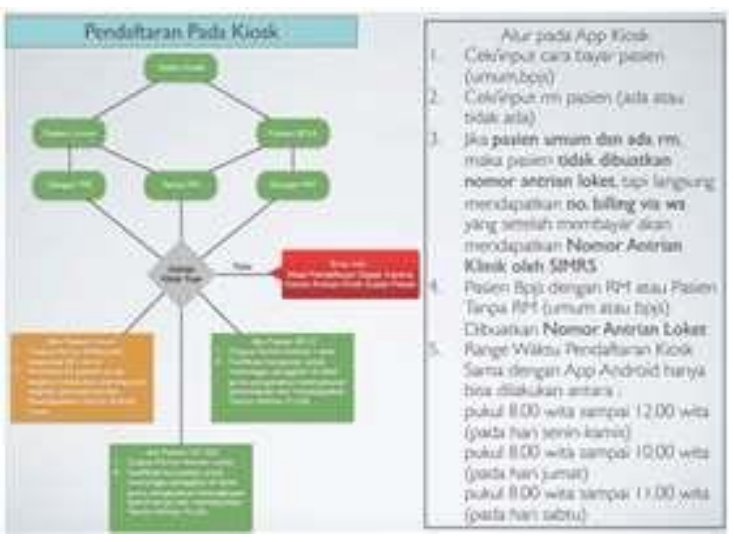

Gambar 5. Alur Proses system antrian loket berbasis KIOSK

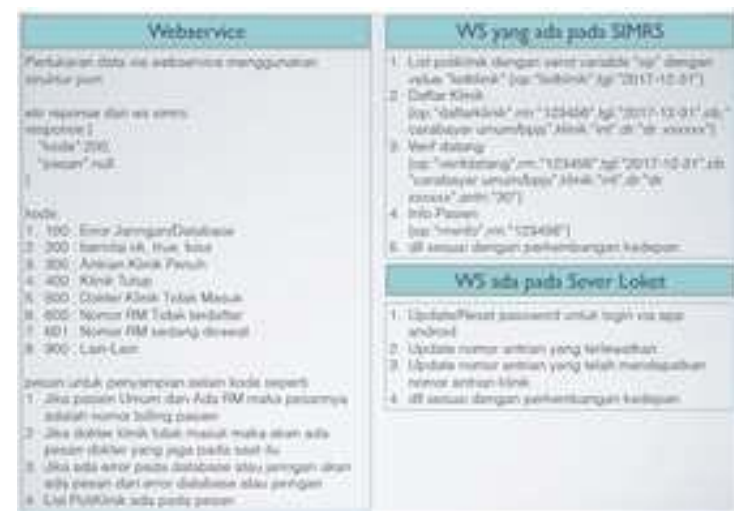

\section{Gambar 6. Rencana Webservice untuk integrasi sistem antrian dengan SIMRS}

Setelah perancangan Alur (algoritma) system dan API (webservice) sehingga terbentuk rancangan use case diagram, siapa saja actor pengguna aplikasi ini

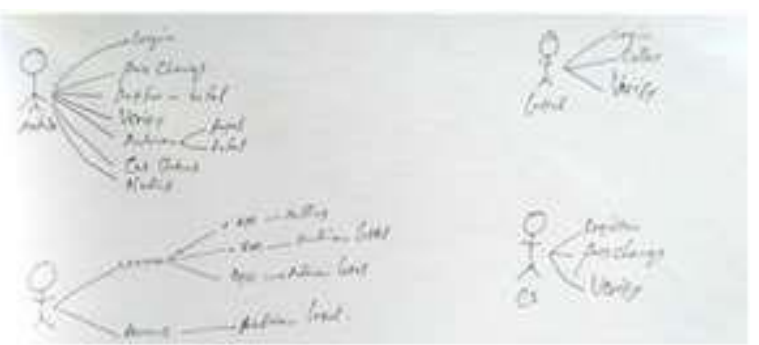

Gambar 7. Use case diagram

Desain struktur database untuk system pendaftaran antrian online yang terintegrasi dengan SIMRS sebagai berikut: 


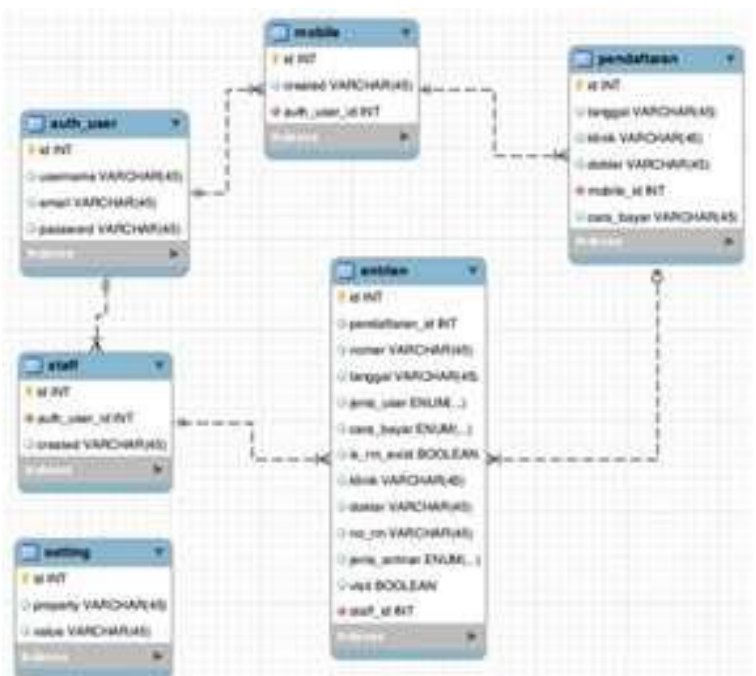

Gambar 8. Desain database

Database ini desain begitu kompleks, untuk mendukung pengembangan selanjutnya pada Sistem Antrian. Sehingga Sistem ini dibangun dengan fitur-fitur yang dinamis. Desain struktur Database tersebut berdasarkan aplikasi mobile (android) agar kemudahan dalam integrasi sistem menyeluruh.

\section{IMPLEMENTASI}

Setelah melalui tahap Analisa dan perancangan system maka selanjutnya adalah pembuatan system yang di mulai dari pembuatan webservice

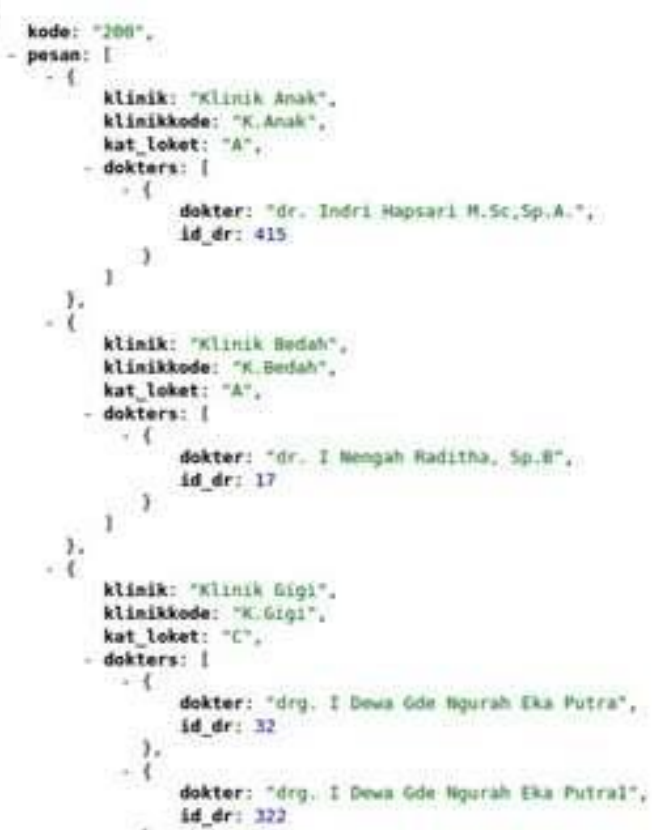

Gambar 9. Contoh Script API akses Klinik
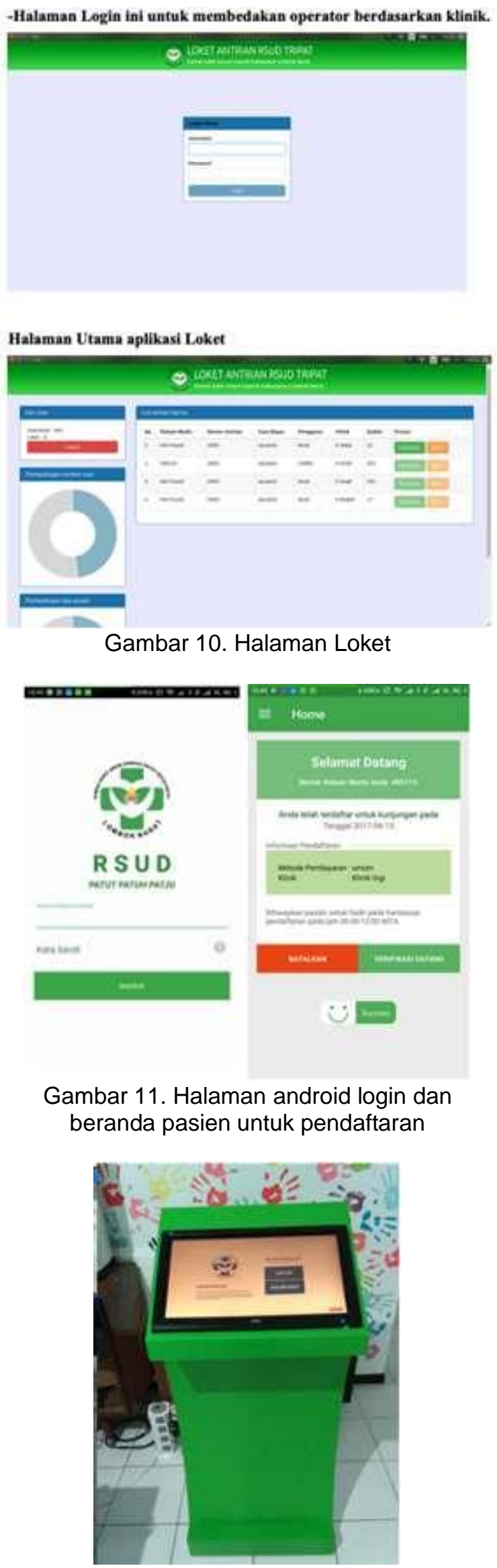

Gambar 12. Mesin Kiosk antrian

Sistem Antrian Loket, KIOSK dan Android Terintegrasi SIMRS RSUD Patut Patuh Patju Gerung 


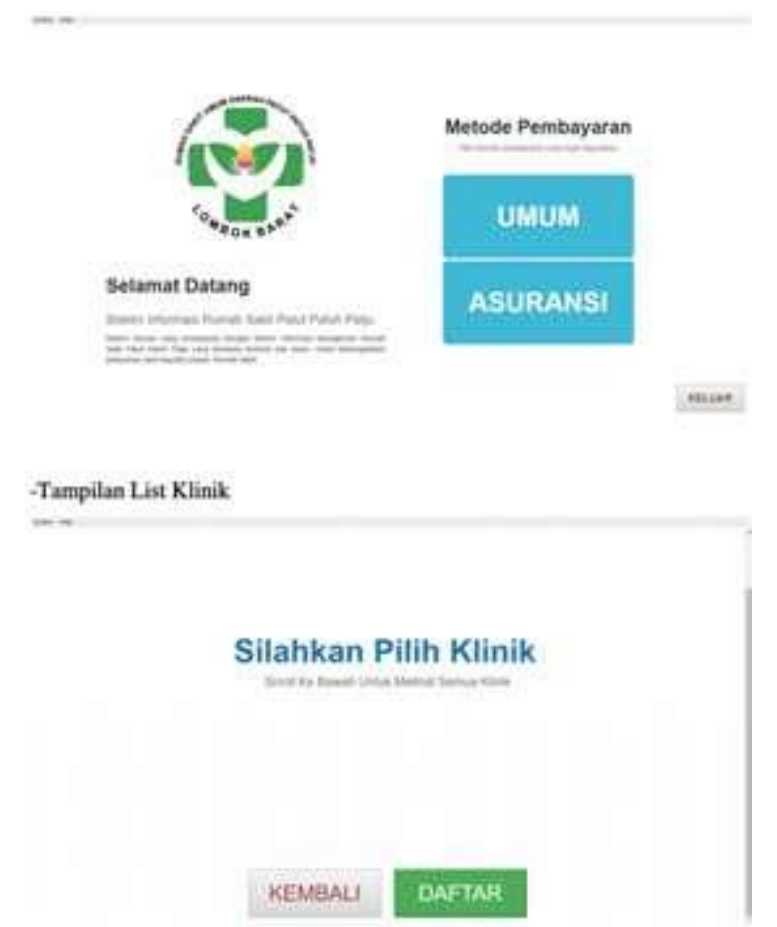

Gambar 12. Halaman KIOSK antrian

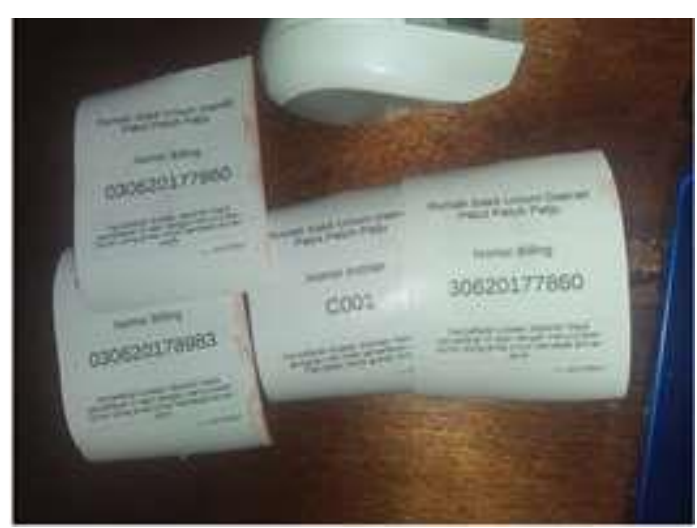

Gambar 13. Hasil Print kertas antrian pasien dari mesin kiosk

\section{KESIMPULAN}

Setelah melalui berbagai tahapan perencanaan Sistem antrian online berbasis Android dan mesin kiosk yang terintegrasi SIMRS. Semua antrian pasien online maupun yang datang langsung melalui mesin kiosk terintegrasi dengan SIMRS Sehingga pelayanan kepada pasien berbasis teknologi ini mempercepat waktu pelayanan.

Kesimpulan yang didapat dalam pembahasan penelitian ini adalah sebagai berikut :

1. Pengguna Sistem terdiri dari : Pasien, operator loket dan operator SIM masing-masing layanan poli.

2. Dengan adanya system ini harapannya mempercepat waktu pelayanan pasien dan mempermudah alur pendaftaran pasien

\section{DAFTAR PUSTAKA}

[1] Kominfo, 2018, Indonesia Raksasa Teknologi Digital Asia: kominfo.go.id

[2] Kotlin, 2020, https://kotlinlang.org/

[3] Python. 2018. http://www.python.org/about/apps.

[4] Brian K. Williams, Stacey C. Sawyer, Using Information Technology: A Practical

[5] William J., \& Sri L.S. 2015. Sistem Informasi UKM Berbasis Website Pada Desa Sumber Jaya. Jurnal Informatics and Businnes Institute Darmajaya, Vol. 01, No. 1.

[6] Josi, A. 2016. Implementasi Framwork Boostrap Pada Website STMIK Prabumulih. Jurnal Mantik Penusa. Volume 20 No 1. ISSN:2088-3943.

[7] Sudarto, H.P. 2018. Perancangan Website Sebagai Media Promosi dan Informasi. Journal Of Informatic Pelita Nusantara. Volume 3 No 1.

[8] EMS, Tim, 2014. Teori dan Paktik PHP MySQL Untuk Pemula. Jakarta: PT. Elex Media Komputindo. 